\title{
Action of nitric acid on brucia
}

\section{M.Aug. Laurent}

To cite this article: M.Aug. Laurent (1848) Action of nitric acid on brucia, Philosophical Magazine Series 3, 32:216, 392-393, DOI: 10.1080/14786444808646003

To link to this article: http://dx.doi.org/10.1080/14786444808646003

$$
\text { 册 Published online: } 30 \text { Apr } 2009 .
$$

6 Submit your article to this journal $\pi$

LII Article views: 2

Q View related articles $\asymp$ 
Jan. 20.- "On the Heat disengaged during Metallic Substitutions." By Thomas Andrews, M.D., M.R.I.A., Vice-President of Queen's College, Belfast, \&c. Communicated by Michatl Faraday, Esq., D.C.L., F.R.S. \&c.

In a paper which was published in the Philosophical'Transactions for 1844 , the author deduced from the experimental inquiry there recorded the general law, that when one base displaces another from any of its neutral combinations with an acid, the heat evolved or abstracted is always the same, whatever that acid element may be, provided the bases are the same. Extending a similar inquiry to salts with metallic bases, he establishes, as the result of the investigation of which an account is given in the present paper, the general principle that when an equivalent of one and the same metal replaces another in a solution of any of its salts of the same order, the heat developed is, with the same metals, constantly the same, the expression "of a solution of the same order" being understood to mean a solution in which the same precipitate is produced by the addition of an alkali, or, on one view of the composition of such salts, in which the metal exists in the same state of oxidation. The metallic salts, in the precipitation of which by other metals the evolved heat was ascertained, were those of copper precipitated by zinc, iron or lead; of silver, precipitated by zinc or copper; and of lead, mercury, and platinum precipitated by zinc: and the acid elements were either the sulphuric, hydrochloric, acetic or formic acids. From the last series of experiments the author deduces, that if three metals $A, B$, and $C$, be so related that $A$ is capable of displacing $B$ and $C$ from their combinations, and also $B$ capable of displacing $C$, then the heat developed in the substitution of $A$ for $C$ will be equal to that developed in the substitution of $A$ for $B$ added to that developed in the substitution of $\mathrm{B}$ for $\mathrm{C}$; and a similar rule may be applied to any number of metals similarly related.

\section{Intelligence and Miscellaneous Articles.}

ACTION OF NITRIC ACID ON BRUCIA. BY M. AUG. LAURENT.

T $T$ is well known to chemists that brucia, when treated with nitric acid, becomes of a very intense red colour. Some time since, M. Gerhardt, on examining this phænomenon attentively, observed that there was disengaged at common temperatures, a gaseous body slightly soluble in water, which had a very decided smell of apples, and burnt with a yellowish flame, accompanied with nitrous vapours. For want of material M. Gerhardt did not continue his observations ; nevertheless he concluded from them that the gas disengaged from brucia is nitrous ather.

M. Liebig has repeated this experiment, and expresses himself as follows in the miserable diatribe which he has aimed at us :- "The production of nitrous ather by a body which contains neither alco. hol nor æther appears to me as remarkable as it is important in the history of æthereal combinations, on which account I undertook to repeat the experiments of $M$. Gerhardt. I condensed a portion of the gas which is disengaged from the brucia, and obtained a liquid 
which was immiscible with water, was more dense than dilute nitric acid, and boiled at from $158^{\circ}$ to $167^{\circ} \mathrm{F}$."

Not being able to conceive how a gaseous body at common temperatures could yield a liquid which boils only at $158^{\circ}$ to $167^{\circ} \mathrm{F}$., I resolved in my turn to repeat the experiment of $M$. Gerhardt.

I operated on 15 to 20 grammes of brucia. After having passed the gas over lime, I condensed it in a U-shaped tube, having at its curvature a small tube terminated by a bulb; by the help of a mixture of ice and salt I obtained about 1 gramme of a very fluid liquid, which was lighter than water, and had a strong smell of apples. I slowly distilled this liquid, almost to the last drop, at a temperature approaching $50^{\circ} \mathrm{F}$., and without making it boil; I then submitted it to analysis; $0.550 \mathrm{gr}$. of the substance yielded 0.553 of carbonic acid and 0.290 of water. Nitrous æther contains-

\begin{tabular}{|c|c|c|c|}
\hline$C^{2} \ldots \ldots \ldots$ & 24 & $\begin{array}{c}\text { Calculation. } \\
32^{\circ} 0\end{array}$ & $\begin{array}{c}\text { Experiment. } \\
29^{\circ} 0\end{array}$ \\
\hline $\mathrm{H}^{5} \ldots \ldots$ & 5 & $6 \cdot 6$ & $6 \cdot 1$ \\
\hline$N \ldots \ldots$ & 14 & $\cdots$ & \\
\hline $\mathrm{O}^{2} \ldots \ldots$ & 32 & . & \\
\hline & 75 & $\overline{100}$ & \\
\hline
\end{tabular}

The hydrogen and carbon are precisely in the same proportions as in nitrous æther. As to the loss, it is easily understood, when the smallness of the quantity of the liquid which I possessed, and the difficulties attendant upon the analysis of so volatile a substance, are considered.

Nitrogen was disengaged during the whole of the operations. Though the relations which exist between the composition, the atomic weight and boiling-points have been but slightly considered, it will be readily seen to be impossible that a substance which does not contain more than 29 to 30 per cent. of carbon and 6 of hydrogen, should contain more than $\mathrm{l}$ atom of nitrogen; for if we double the formula by putting either $\mathrm{C}^{4} \mathrm{H}^{10}$ or $\mathrm{H}^{9}$, or $\mathrm{H}^{8} ; \mathrm{N}^{2} \mathrm{O}^{4}$ or $\mathrm{O}^{5}$, a similar combination would have a boiling-point much higher than $50^{\circ}$ or $60^{\circ} \mathrm{F}$.

This experiment has also been repeated by M. Fournet, who also obtained a liquid possessing all the properties of nitrous æether.Ann de Ch. et de Phys., Avril 1848.

ON CACOTHEI.IN. BY M. AUG. LAURENT.

When nitric acid has ceased to act upon brucia at common temperatures, it deposits a crystalline substance of a fine orange-yellow colour, which the author has named cacothelin. It is insoluble in water and slightly soluble in alcohol. When kept in a stopped bottle, and exposed to diffused light, it quickly becomes brown on the surface. By analysis it gave results which indicated the annexed formula :- 